\title{
The Semantics and Perception of ME Happiness in The Canterbury Tales
}

\author{
Agnieszka Wawrzyniak \\ Department of English Studies, The Faculty of Pedagogy and Fine Arts, Adam Mickiewicz University, Kalisz, Poland
}

Copyright $\mathrm{C} 2018$ by authors, all rights reserved. Authors agree that this article remains permanently open access under the terms of the Creative Commons Attribution License 4.0 International License

\begin{abstract}
The aim of the paper is to focus on the conceptual construal of ME happiness in The Canterbury Tales in order to reconstruct the culture in Chaucer's world. The analysis is based on The Canterbury Tales (The British Library Copies edited by Barbara Bordalejo). The paper will refer to the etymology of the lexemes that constituted the concept of mediaeval happiness as well as to their semantic similarities and differences. Furthermore, the attempt is also to juxtapose Middle English and Present Day English concepts of HAPPINESS thereby reflecting on two distinct cultures and hence on two distinct worldviews. In my study I will refer to works by Wierzbicka $(1991,1992)$ in an attempt to recreate world out of words (Bartmiński and Tokarski 1993).
\end{abstract}

Keywords Happiness, Mediaeval, Ideology, Culture, Concept

\section{Introduction}

The aim of the paper is the attempt at analysis and recognizing an abstract, existential nature of HAPPINESS, hence of a concept that was essential in the history, but which is also fundamental for the contemporary society.

The paper focuses on the construal of ME concept of HAPPINESS in The Canterbury Tales [1], and juxtaposes Middle English and Present Day English concepts of HAPPINESS thereby reflecting on distinct cultures and distinct worldviews. It aims to show that concepts of happiness vary across cultures and in historical times. Apart from the lexeme happy, the analysis focuses on such lexemes as selly, bliss/blissed and mery in order to reconstruct the holistic perception and conceptualization of HAPPINESS for the mediaeval society and to "recreate world out of words" (Bartmiński and Tokarski 1993) [2]. The paper will refer to the etymology of the lexemes, as well as to the semantic similarities and differences between them. The study will also focus on the variety of collocations that coded these lexemes in order to reflect upon cultural beliefs and social values of HAPPINESS for the mediaeval society. The analysis of frequent collocations and then the juxtaposition of the linguistic context with other types of contexts, such as historical, cultural and social, will cast a different perspective upon the studied linguistic items. In other words, changes in the perception of this concept will be accounted for with an attempt at recognizing social, historical factors and cultural norms that could possibly affect the value of HAPPINESS in the two periods.

The analysis utilizes Caxton's The Canterbury Tales: The British Library Copies (ed. by Barbara Bordalejo), which is a CD-ROM containing the first full- colour facsimiles of William Caxton's first and second editions of Geoffrey Chaucer's The Canterbury Tales. This is also the first-ever electronic publication of the full text of all copies of the Caxton edition. The study is based on all contexts in which selly, happy, hap, blissed, bliss and mery were recorded. In order to achieve maximum accuracy, the data is also supported by the online Middle English Dictionary (MED) [3], and by the online Etymological Dictionary [4].

\section{The Semantic Analysis of ME Selly}

Following the online Etymological Dictionary of English (sv. selly), ME selly is related to OE gescelig 'happy, fortuitous, prosperous; salig (O.S), salich (M. Du), salig (OHG), sels (Goth), which denoted 'blessed, happy, blissful. The word originated from PIE *sele' of good mood; to favour'.

The analysis of The Canterbury Tales reveals that selly was a subject to pejoration as it underwent a shift from the originally positive sense of 'happy' or 'blessed' to 'wretched', 'unfavourable' and 'miserable'. In the study 22 contexts were documented that encoded selly. Moreover, the analysis of The Canterbury Tales records the following senses of selly: 
Table 1. The senses of selly in The Canterbury Tales

\begin{tabular}{|c|c|}
\hline sense & tokens \\
\hline happy, blessed, innocent & 4 \\
\hline gullible, foolish & 8 \\
\hline wretched, miserable, pitiable & 9 \\
\hline happy, frivolous & 1 \\
\hline
\end{tabular}

In other words, three major stages can be observed in the development of the analyzed lexeme:

stage (1): spiritually favoured, blessed, innocent

stage (2): gullible, ignorant, doting

stage (3): wretched, unfortunate, miserable, pitiable

The subsections to follow will aim at analyzing the semantics of the particular stages.

\subsection{The Semantic Analysis of Happy, Blessed, Innocent}

The evaluation of stage (1), hence of the senses 'happy, blessed, innocent' is based on more objective criteria, that is, on the canon of norms which may qualify a person as happy, rather on subjective judgements.

To begin with, the concept of happiness was grounded in religion and had a different dimension than the contemporary understanding of the idea of happiness. Happiness was not perceived as personal and attainable. There was a close link between being moral, virtuous and happy. In other words, the concept of happiness associated with the early sense of selly corresponds to the socio-physical world of reference. It is grounded in religion and is based on objective values. Consequently, real happiness is pure and free from worldly interest. A person feels happy if he/she constantly avoids sins. Final happiness was believed to consist in a supernatural union with God. Human happiness was believed not to consist of wealth, pleasure not of any earthly goods.

Moreover, a happy person evoked connotations of the one who is spiritually favoured and blessed, but also fine, noble and virtuous.

As a consequence, the rendition of someone as a happy person did not reflect a subjective, egocentric approach to the concept of happiness based on individual's feelings of self-commitment, or satisfaction, but rather it encoded a normative character and a system of norms in the light of which the person could be referred to as happy, therefore blessed.

Furthermore, the dividing line between 'blessed' and 'innocent' was blurred. Blessed, like innocent, was correlated with grace from God. Innocence is thus grounded in the religious sphere. The person labelled as innocent is also inexperienced, sinless, moral and virtuous. Hence, a lack of experience evoked positive associations as it was related to a lack of opportunities to sin.

Additionally, selly, in the sense of blessed and innocent, was a modifying adjective to describe children and women. As has already been indicated, the attribute of innocence was grounded in the religious sphere rather than on subjective judgements. The sense of 'happy, blessed, innocent' in selly can be exemplified by the following contexts:

(1) For sely child wolalweysoonelere. (The Prioress Tale60)

(For the innocent child will always learn soon).

(2) For drede of wrechesaue Constance alone

Greet was the drede and eke the repentaunce

Of him that hadde wrong suspection

Up on this sely Innocent Constaunce (....) (The Man of Law's Prologue 581-589)

(From the dread of punishment save Constance alone; great were the dread and also the repentance of the one who had the wrong suspicion of the Innocent Constance).

\subsection{The Semantic Analysis of gullible, Ignorant, Doting}

The semantic analysis of stage (2), hence of the senses 'gullible, ignorant, doting' shows that the attribute of 'gullibility' was emotionally marked. The element that is shared by both stages is 'the idea of being inexperienced'. As already indicated, a lack of experience, when mapped on the religious sphere, evokes purity and being sinless. Nevertheless, a lack of experience, when mapped on other contexts, implies negative associations, namely being gullible, ignorant, and easy to manipulate. Therefore, at stage (2), selly could function as a euphemism. It was a polite epithet that could have an additional, underlying meaning between the lines. Selly gradually started to lose positive associations in favour of negative ones. The concept of gullibility can be exemplified by the following contexts:

(3) The selyhousbondealgate he mot paye. (The Shipman's Tale 11)

(The gullible husband by all means should pay).

(4) And eke hendy Nicholas and Alison

Acordid be fully to this conclusion

That Nicholas shalshapenhym a wyle

This selyielous husband to begyle. (The Miller's Tale215-218)

(And moreover, the courteous Nicholas and Alison fully agreed on this conclusion that Nicholas should shape him for a while in order to beguile this gullible and jealous husband).

Similarly, the collocation 'selly innocent', put in a negative context, evokes a euphemistic understatement, as in the example: 
(5) O sellypreest o selly Innocent

$\mathrm{O}$ graceless fulblynd is thy conceit (The Canon's Yeoman's Tale 357)

(Oh naive priest, oh innocent in his blessing; oh graceless completely blind is your mind).

According to Wawrzyniak [5], the sense of gullibility in selly was marked by subjective judgement, not by the canon of norms rooted in religious values. The sense is thus internally motivated. Moreover, selly performed the function of an euphemism as the lexeme started to be implied in a circuitous and polite way to the descriptions of people or activities that were perceived as negative. Speakers articulated it in order to avoid being called impertinent or rude.

\subsection{The Semantic Analysis of Miserable, Pitiable, Wretched}

The analysis shows stage (3) to be the most subjective. The speaker overtly expresses a critical judgement in light of his/her own attitude toward a person that is the subject of his/her considerations. In this way, a highly pejorative meaning is evoked, which can be exemplified by the contexts:

(6) He starith and woodith in his aduertence

To whom almachesayde o selywrecche

Ne wotist thou how fer my might may strecche (The Nun's Tale 468-469)

(He stares and goes mad in his attention; to whom everybody said - oh worthless wretch; you don't know how far my might may stretch)

(7) selypoure creature (The Clark's Tale 948)

(8) This selly widow and hirdeughtris two

Herden the hennyscrye and make woo (The Nun's Priest's Tale 555-556)

(The wretched/miserable widow and her two daughters heard hens cry and made the lamentation).

\subsection{The Semantic Analysis of the Sense 'Frivolous' in Selly}

The corpus records one sense of selly, namely 'frivolous' which seems isolated and does not fall into the category of three broader stages. It reflects Chaucer's enthusiasm to play with words.

(9) That man shalyelde to his wyf her dette

Where which he make his payement

Yf he ne usid his sely instrument (The Wife of Bath's Prologue 132)

(That man should yield to his wife her debt; how else should he make his payment; if he didn't use his 'blessed' instrument).

Chaucer uses here the technique of playing with words; he takes lexemes which were grounded in the social, normative sphere, and gives them a different tone, thereby modifying the conventional, socio-cultural core meaning of the early sense. The analysis of selly in Chaucer's Tales shows that the lexeme was highly polysemous. In some contexts, the lexeme evoked attributes that were in line with the mediaeval conceptualization of happiness (blessed state, innocence, purity of the soul), while in others the lexeme is the euphemism selected with the view to criticize human vices. Finally, selly also functions as the adjective that is negatively loaded or in satirical, grotesque contexts to highlight irony.

\section{The Semantic Analysis of MEHappy}

According to the online Etymological Dictionary, happy is related to A.S. gehop, Icel. happ, which denoted the sense 'chance, fortune, good luck'. Following the online Middle English Dictionary (s.v. happy), happy possessed the following senses:

(1) favoured by fortune, fortunate, prosperous, lucky, being in advantageous circumstances;

(2) of an event, action; lucky, turning out well, favourable (season)

The analysis in The Canterbury Tales records only two senses of happy, which shows that the lexeme was infrequent in Middle English. Moreover, it evoked also different senses than PDE 'happy', namely:

favoured by fortune, prosperous, lucky

(10) Yf an erlisdoughter be riche, she may chese a thousand

men whom she wil take to her husbonde (....). Yf thou be right

happy that is to say yf thou be riche thou shalt fynde a grete

nombre of felaws and frendes, and yf thy fortune change

farewel friendship and felawship for thou shalt be alone

withoutcompanye (The Tale of Melibee 588)

(If an earl's daughter is rich, she may choose a thousand of men whom she will take as her husbands. If you are truly happy, that is to say if you are rich you will find a great number of fellows and friends, and if your fortune changes; farewell friendship and fellowship for you will be alone without company);

favoured by God 
(11) Wel happy and blessed be tho that louen and purchasen

pees. For they be called chyldren of god (The Tale of Melibee 710)

(Truly happy and blessed will be the one that loves and purchases peace, for they will be called children of God).

Approaching these contexts, the etymology of happy and its senses in the online Middle English Dictionary, the concept of happiness evoked by happy appears to correlate with a state brought about by the external force (luck, fortune). It is not attainable within one's reach, but rather obtainable via a divine gift, or by chance, fortune. Furthermore, the noun hap frequently co-occurred with fortune in The Canterbury Tales, as in the following contexts:

\section{hap of fortune}

(12) O sodeyn hap of fortune variable. (The Merchant's Tale 813)

(Oh sudden stroke of fortune variable)

hap and fortune

(13) He stands in drede of hap and fortune. (The Shipman's Tale 237)

(stand in fear of lack and fortune)

fortune sends X hap

(14) Fortune hym sent suche hap that he ascaped through the rayn. (The Monk's Tale 651-652)

(Fortune sent him such luck that he escaped through the rain).

The study has indicated that the semantics of ME happy did not run in parallel to the semantics of PDE happy. To begin with, ME happy was infrequently used. There were only two contexts recorded that codified happy. Secondly, the semantics of ME happy did not correspond to the semantics of its PDE apparent equivalent. ME happy denotes two senses. If used in the secular context, the lexeme stands for 'lucky', 'rich' and 'prosperous'. In the religious context, happy means 'favoured by God and blessed'. In both contexts, however, happy is contingent upon the external force (fate or God). Yet, in the sense 'favoured by fortune', the aspect of a chance to be prosperous is highlighted, whereas the sense 'favoured by God' is grounded in the religious values and commonly cherished norms.

\section{The Semantic Analysis of MEMery}

According to the online Etymological Dictionary (s.v. merry), mery is related to MD mergekijc 'joyful'. The word originated from PG murgijaz 'short-lasting', and from PIE root mregh 'short'. The Middle English Dictionary (MED) records the following senses in mery:

(1) cheerful by nature or in disposition

(2) maken/werken merry 'make happy'

(3) of words - causing happiness

Moreover, as stated in the MED, mery was also associated with physical attractiveness and youth. Additionally, unlike selly or happy, merry in all contexts was related to the concept of earthly happiness, joy, pleasure and cheerfulness. Consequently, mery did not constitute the normative and based on religious values concept of happiness and blessedness. Yet, the reasons for analysing the concept of mery are as follows:

To begin with, the present paper aims to juxtapose both mediaeval and PDE concepts of happiness. Merry belongs to the category of lexemes that constitute the PDE conceptualisation of happiness as it refers to a state that is 'cheerful and happy', thereby fitting into the modern category of happiness. In other words, merry is one of building blocks of PDE concept of happiness, which is, however absent in the concept of happiness projected in Chaucer's Tales.

Secondly, the lexeme was used in Chaucer's Tales to conceptualize the concept of an earthly joy and cheerfulness, thereby setting a background for the holistic comparative analysis of various lexical items constituting various types of joy, namely bodily joy, conceptualised by mery, as opposed to religious one, conceptualised by selly, blissed/bliss etc., which build up the mediaeval idea of happiness.

Thirdly, MEmery was an item of a high frequency and applied to a variety of collocations, as opposed to ME happy, which was a rare item. Hence, the juxtaposition of ME happy and mery with PDE happy and merry is vital because of the differences in the frequency of the usage and the semantic attributes evoked by Middle English items and their apparent PDE equivalents.

The analysis in The Canterbury Tales records 40 instances of contexts that codify mery. The central sense of mery in the corpus is 'cheerful' ( 20 tokens). The distribution of this sense is quite broad as mery performed the function of the modifying element used with reference to people, events, parts of the body and animals. The distribution and the tokens of the sense 'cheerful' were recorded with reference to the following items:

- people (8 tokens): man 'man' (The General Prologue 737; 757), companye 'company' (The General Prologue 758; 764), weddid man ' the wedded man' (The Merchant's Tale487), contre 'country' (The Clark's Tale 615), husbond 'husband' (The Man of Law's Tale 3029), chyld 'child' (The Miller's Tale 139)

- parts of the body (4 tokens): chere (The Man of Law's Tale 36), throte 'throat' (TheMiller's Tale 32), herte 'heart' (The Man of Law's Tale 3029), steuyn 'voice' (The Nun's Prologue 471) 
- events (7 tokens): day 'day' (The Knight's Tale 641, The Merchant's Tale 808), lyf 'life' (The Miller's Tale 158, The Merchant's Tale 401), Cristmasse 'Christmas' (The Man of Law's Tale28), meel 'meal' (The Summoner's Tale 66), thing of auenturis 'aspect of an adventure' (The Clark's Tale 15)

- animals (2 tokens): larke 'lark' (The Knight's Tale 633), nychtyngale 'nightingale' (The Wife of Bath's Prologue 458)

The other sense of mery was 'causing happiness'. In this sense, mery could be applied with regard to words and objects:

- words (5 tokens): tale 'tale' (The Clark's Tale 9, The Man of Law's Tale 2846, The Man of Law's Tale 3746), note 'note' (The General Prologue 802), prologue 'prologue' (The General Prologue 802)

- objects (1 token): belle 'bell' (The Shipman's Tale 824)

Additionally, mery was also recorded in the variety of collocations, and in the simile:

- make x mery (3 tokens) 'make sb. merry, cheerful' (The General Prologue 802, The Canon Yeoman's Tale 476, The Parson's Tale 555)

- in collocations centralizing chere 'face, appearance' (4 tokens): a merychere ' a cheerful face, appearance' (The General Prologue 857, The Shipman's Tale 342), mery of chere 'of cheerful appearance' (The Man of Law's Tale 36), mery and glad of chere 'cheerful and glad of appearance' (The Parson's Tale 635)

- accompanied by other adjectives and/or adverbs: mery and joyous 'cheerful and joyful' (The Merchant's Tale 104), yong and mery 'young and cheerful' (The Merchant's Tale 974), mery and glad 'cheerful and glad' (The Merchant's Tale 1172), fulmery and wel at ese 'fully cheerful and well at ease' (The Nun's Priest's Tale 439), wanton and mery' immoral and cheerful' (The General Prologue 209)

- simile (1 token): as mery as a nychtyngale ' as merry as a nightingale' (The Wife of Bath's Prologue458)

The analysis shows that MEmery was mostly associated with cheerfulness, youth, joy and pleasure, hence superficial values rather than with deep and religious ones. In the collocations, mery was a descriptive element of chere 'face, appearance', thus of the external aspect of a human. Additionally, the lexeme was co-occurring with such adjectives as: yong, glad, wanton, or an adverb wel at ese.

The other aspect worth considering in the semantic framework of mery is the distribution related to modified entities. To begin with, as for the sense 'cheerful', mery wasmostly used with reference to people. The reference to humans could be direct, or indirect via metonymic extensions to the parts of the body and events. In other words, mery could apply to humans via the parts of the body (e.g. merychere), therefore reflecting the metonymous link: the part stands for the whole, where the happy face stands for the happy person. The other metonymous extension in the semantics of mery is happy/cheerful event stands for the people participating in it. Hence, a cheerful meal, or a cheerful day metonymically stands for the person that is cheerful during the whole event, thereby emphasising the link of the cause standing for the result. Additionally, mery referred also to animals, yet this distribution was marginal. With regard to the sense 'causing happiness', mery was mostly applied with reference to words, rather than to objects.

The semantics of ME mery could be exemplified by the following contexts:

(15) Now leetvssitte and drynke and make vsmery (The Parson's Tale 555)

(Now let us sit and drink and make us happy/cheerful).

(16) Womennyscounceyllis be ful ofte colde

Womennyscouncelbroughtevs first to woo

And made adamfroparadis to go

There he was fulmery and wel at ese (The Nun's Priest's Tale 436-439).

(Women's counsel is often cold; women's counsel brought us first to lamentation and made Adam leave the Paradise; there he was fully cheerful and well at ease).

\section{The Semantic Analysis of MEBliss/Blissed}

According to the online Etymological Dictionary, both bliss, blissed originated from OE bliss and blips 'bliss, merriment, happiness, grace, favour', and from PG *blithsjo/blithiz 'gentle, kind'. Originally bliss applied to earthly happiness. In later Old English the lexeme referred to spiritual joy, perfect felicity/happiness and the joy of heaven.

\subsection{Bliss}

The insight into the online Middle English Dictionary and the analysis of The Canterbury Tales record the following senses of bliss:

- harmony, state of ecstasy, bliss between lovers or spouses (8 tokens) (The Miller's Tale 977; 1021, The Merchant's Tale 42; 96; 368; 468; 527, The Franklin's Tale 836)

- eternal bliss in heaven, the place of perfect bliss $(9$ tokens) (The Man of Law's Tale 1043, The Miller's Tale 298, The Merchant's Tale 1174, The Franklin's Tale 529, The Pardoner's Tale 584, The Nun's Prologue 626, The Parson's Tale 718; 758; 1002)

- a happy condition, well-being, prosperity (1 token)(The Man of Law's Tale 637) 
- joy, gladness (1 token) (The Knight's Tale 591)

The study, based on The Canterbury Tales, lists 15 contexts that codify bliss. The lexeme in its prototypical senses conceptualized harmony/ecstasy between lovers and eternal bliss in heaven. In other words, bliss echoed religion, ideology, or a deeply felt emotion.

The concept of the eternal bliss could be exemplified by the following contexts:

(17) Make vs all good men

And bringevs to his high blisse amen (The Nun's Priest's Tale 627)

(Make us all good people and bring us all to the high bliss. Amen);

(18) blisse of heaven (The Parson's Tale 758; 718) 'bliss of heaven'

(19) endelessblisse of heaven (The Parson's Tale 760) 'endless bliss of heaven'.

The concept of ecstasy/bliss between lovers could be exemplified as follows:

(20) Wel may his herte in ioye and blissehabounde (The Merchant's Tale 42)

(Well may his heart abound in joy and bliss).

(21) The blisse that is betwix hem twey

Ther may no tungetelle or hertethynke (The Merchant's Tale 96-97)

(The bliss that is between them two; there is no tongue that would be capable of expressing neither it nor heart capable of thinking of it).

\subsection{Blissed}

The analysis records 6 contexts in The Canterbury Tales, all of which linked with the religious sphere and evoking the sense 'perfect, blessed':

(22) my blissed lady deer (The Knight's Tale 1402) 'my blessed dear lady'

(23) blissed mary (The Man of Law's Tale 822) 'blessed Mary'

(24) father blissed (The Clark's Tale 577) 'blessed father'

(25) our blissed lady Cristismoderdere (The Parson's Tale 58) 'our blessed lady Christ's mother'

(26) blissed mayde (The Prioress Tale 212) 'blessed maid'

(27) blissed company (The Parson's Tale 1003) 'blessed/holy company'

The semantics of bliss/blissed show that these lexical forms evoked deep undertones. ME bliss was used with a view to projecting 'bliss of heaven or of love', whereas the application of blissed was restricted only to the religious sphere to refer to the perfect, the blessed.

\section{The Contemporary English and the Mediaeval Concepts of Happiness}

The juxtaposition of the contemporary English and the mediaeval concepts of happiness showed that they were positively loaded for both cultures, yet they were underpinned by divergent values.

Lexemes which coded the concept of happiness in Middle English could be referred to as 'big words' as they echoed religion, ideology, or a deeply felt emotional state. In other words, the central senses of lexemes that codify happiness are grounded in religion and are based on objective values. They reflect a close link between being moral, immaculate, virtuous and happy. Moreover, for the mediaeval society, happiness is conceived as a state that comes from the outside, hence it is equalized with the external force. It is also viewed as the ideal state, which is hardly attainable. Furthermore, the state of happiness is synonymous with the state of blessedness and is inextricably bound with the human soul.

By contrast, the contemporary English society pushed the concept of happiness from the religious into the secular area. Additionally, it is viewed as personal, subjective and attainable rather than as external and objective. The concept of happiness is thus associated with subjective well-being and is centred on wide range of positive inner feelings, rather than with rare events or conditions. Similarly, Diener [9] equalizes happiness with the presence of pleasant emotions, and the absence of unpleasant emotions. He also claims that the English use this concept along with 'excitement'. Happiness has thus more personal character than in Middle English and is not based on the concept of sin or virtue, but rather on emotions and moods. Morality is not the reference point, or a building block in the construal of the conceptualization of happiness. The person can feel happy even if his or her way of behaviour is not acceptable. On the other hand, other people need to make sacrifices to feel good about themselves. The contemporary view of happiness is hence more elusive. It cannot be defined by any readily made criteria, or necessary and sufficient conditions. What makes one happy is what one feels or thinks that may make him happy or joyful. In other words, the contemporary perception of happiness escapes a definition. It is based on subjective judgement and need not be correlated with the generally accepted system of norms and values. The rendition of someone as happy reflects individual and egocentric approach to the concept of happiness based on such feelings as satisfaction, and/or self-commitment.

Furthermore, happiness is not perceived as an idealistic state, but as a state which is within one's reach. Hence, happiness is viewed as a positive emotion, such as contentment, or joy. It does not echo religion or any other ideology. For Wierzbicka [8], it evokes good rather than very good feelings. Moreover, these feelings can be achieved and experienced by many people as well as for 
long periods. It is a state that can be attainable by anyone. 'Being happy' is an every- day expression rather than 'a big word' and is frequently synonymous to 'being glad, or joyful'. It is also Wierzbicka [6], [7] who maintains that the threshold for 'being happy' in English is much lower than in other languages. She emphasizes that the English term 'happy' is used much more 'liberally' (Wierzbicka [8] than its equivalents in other languages. For this reason, The English tend to say 'I will be quite happy to do so' to stress just willingness to act in a particular way.

Additionally, the contemporary concept of happiness is more agentic (Gruber, Mauss, Tamin [10] when juxtaposed with the mediaeval concept of happiness. It is not conceived in terms of luck or fortune, but as a conscious goal. The English emphasize active pursuit of happiness, rather than passive luck. They do not view happiness as something external and fragile, but personal and attainable.

\section{Conclusions}

To conclude, the analysis aimed to explore the semantics of Middle English selly, happy, mery, bliss and blissed, in order to reconstruct the concept of happiness for the mediaeval society and to juxtapose it with Present Day English concept of happiness.

The study showed that Middle English concept of happiness was not egocentric, but pure and free from worldly interest. Moreover, it was based on the norms and values grounded in religion. The state of happiness was thus tightly bound with morality and abiding by ten commandments. By contrast, the conceptualisation of happiness in Present Day English is subjective, egocentric and free from ideologies. As a concept, it is more elusive and ambiguous.

The paper referred to the etymology of the lexemes as well as to the semantic similarities and differences between them. The analysis indicated that except for mery, the remaining lexical senses that constitute ME concept of happiness project innocence, purity and immaculate morality as their central senses.

Furthermore, the analysis indicated that selly was a highly polysemous and that the senses that belonged to stage (1), that is happy/blessed were based on the objective criteria and rooted in religious values. The latter stages in selly are more evaluative, subjective and pejorative. As for mery, it evokes the attributes of joy, pleasure and cheerfulness, hence of elements that project contemporary concept of happiness, but are alien to the mediaeval understanding of happiness. ME happy was recorded only in two contexts; one secular and the other one religious one, both of which were highly contingent upon the external force bringing about the desired state. Bliss denoted both eternal bliss and an ecstasy between lovers, while the semantics of blissed was restricted only to the religious sphere.

\section{REFERENCES}

[1] Bordalejo, Barbara (ed.). Caxton's Canterbury Tales Project: The British LibraryCopies. University of Birmingham, 2003.

[2] Bartmiński, Jerzy, Tokarski, Ryszard. (eds.). O definicjach $i$ definiowaniu[On definitions and defining]. UniwersytetMarii Curie-Skłodowskiej, Lublin, 1993.

[3] Middle English Dictionary Online (MED). Available at: http://quod.lib.umich.edu/m/med (date of access: October 2017).

[4] Etymological Dictionary Online. Available at: http://www.etymonline.com (date of access: October 2017).

[5] Wawrzyniak, Agnieszka "The influence of contextual factors upon the semantics of selly". KwartalnikNeofilologicznyLIX: 85-97, 2012.

[6] Wierzbicka, Anna. Cross-cultural pragmatics. The semantics of human interaction. Mouton de Gruyter, Berlin, 1991.

[7] Wierzbicka, Anna. Semantics, culture and cognition. Universal human concepts in culture-specific configuration. Oxford University Press, New York, 1992.

[8] Wierzbicka, Anna. "Happiness in cross-linguistic and cross-cultural perspectives". Dedalus 133: 34-43, 2004.

[9] Diener, Ed. "Subjective well-being". Psychological Bulletin 95, 542-575, 1984.

[10] Gruber, June, Mauss, Iris, Tamir, Maya. "A dark side of happines? How, when and why happiness is not always good". Perspectives on Psychological Science 6: 222-233, 2011. 